\title{
Strain/stress evaluation of Dorsa Geikie using Chandrayaan-2 Terrain Mapping Camera-2 and other data
}

\author{
A. S. Arya ${ }^{1}$, Joyita Thapa ${ }^{2}$, Abhik Kundu' ${ }^{2 *}$, Rwiti Basu ${ }^{2}$, Amitabh ${ }^{1}$, \\ Ankush Kumar' ${ }^{1}$ and Arup Roychowdhury ${ }^{1}$ \\ ${ }^{1}$ Space Applications Centre, Jodhpur Tekra, Ambawadi Vistar, Ahmedabad 380 015, India \\ ${ }^{2}$ Department of Geology, Asutosh College, 92, S.P. Mukherjee Road, Kolkata 700 026, India
}

\begin{abstract}
The high-resolution panchromatic stereo camera Terrain Mapping Camera-2 (TMC-2) on-board the Indian Chandrayaan-2 mission sends images of the lunar surface at $5 \mathrm{~m}$ resolution with a low to high sunangle from an altitude of $100 \mathrm{~km}$. These images help identify subtle topographic variations and enable mapping of low-elevation landforms, one of which is a prominent $\sim 220 \mathrm{~km}$ long wrinkle ridge called the Dorsa Geikie (DG) lying within Mare Fecunditatis. The favourable resolution of TMC-2 images and the digital elevation models provide opportunities for a detailed structural study of the DG and to reveal crustal shortening, cumulative contractional strain and palaeostress regime responsible for thrust faulting for the first time. The time of deformation and formation of dorsa is also estimated for a holistic spatiotemporal understanding of deformation. This study presents initial analysis of the data received from TMC-2, and the accuracy of the results are likely to improve as the ingredients get amended and evolved in future.
\end{abstract}

Keywords: Displacement-length scaling, lunar contraction, mare fecunditatis, stress/strain evaluation, wrinkle ridges.

THE Chandrayaan-2 mission of the Indian Space Research Organisation (ISRO) launched on 22 July 2019, was the second Indian Lunar Mission. The Terrain Mapping Camera-2 (TMC-2) ${ }^{1}$ on-board the Chandryaan-2 mission is a panchromatic, $5-\mathrm{m}$ resolution stereo imaging instrument. It has a spectral band of $0.5-0.75 \mu \mathrm{m}$ (panchromatic) with along-track scanner having $20 \mathrm{~km}$ swath and is capable of generating 3D images of the lunar surface. On 15 October 2019, TMC-2 got an opportunity to image the lunar surface with a low sun-angle over Mare Fecunditatis from an altitude of $\sim 100 \mathrm{~km}$. This enhanced the subtle lunar topographic variations thus enabling delineation, mapping and morphometry of low-elevation landforms of the region. One such impor-

*For correspondence. (e-mail: kundu.abhik@gmail.com) tant lunar tectonic feature is a wrinkle ridge called the Dorsa Geikie $(\mathrm{DG})^{2}$, an arcuate wrinkle ridge $\left(\sim 1^{\circ} \mathrm{S}\right.$ to $4^{\circ} \mathrm{S}$ and $53.25^{\circ} \mathrm{E}$ to $\left.53.75^{\circ} \mathrm{E}\right)$. Here we have made an effort to reconstruct the tectono-stratigraphic framework of the DG using ortho-images and digital elevation model (DEM). We estimated crustal deformation due to accumulated strain, stress field and age of the DG. Wrinkle ridges, a known type of geomorphic feature on the terrestrial planets, form within the compressional stress regime. The wrinkle ridges originate due to faultpropagation folding of the surface overlying blind thrust faults and are often envisaged as the superposition of a broad arch and asymmetric ridges ${ }^{3-5}$. On the Moon these tectonic features are found predominantly within the lunar mare ${ }^{6}$. Wrinkle ridges are present throughout the mare regions and might have formed even after the emplacement of the recent mare basalt units ${ }^{7,8}$. Origin of these ridges is usually attributed to shifting of the global stress field and its superposition on the local stress field from extensional to compressional as the Moon changed from net expansion to net contraction since it has started cooling post $3.6 \mathrm{Ga}$ (refs 7-11).

Wrinkle ridge systems within Mare Fecunditatis are well developed, specially in the northern and eastern portions with varying levels of deformation (Figure 1) ${ }^{12}$. The Fecunditatis basin is pre-Nectarian and its basalts are of apparently middle to late-imbrian $(3.8-3.2 \mathrm{Ga})$ in age $^{13,14}$. The Luna 16 basalt samples indicate a narrow age range of 3.29-3.38 Ga for Fecunditatis ${ }^{15}$.

Some researchers have suggested the occurrence of three different volcanic phases responsible for geological evolution of this mare ${ }^{16}$. The thickness of the basalt layer in and around the centre of Mare Fecunditatis is thinner $(0.5-0.8 \mathrm{~km})$ compared to that $(\sim 4 \mathrm{~km})$ along the periphery of the basin, with maximum thickness of $4-5 \mathrm{~km}$ occurring towards the margin of the basin. The thickness of the mare basalt in Mare Fecunditatis is thinner compared to other basins like the Tranquillitatis and Porcellarum $^{10}$. Its southwestern edge is faulted by parallel arcuate grabens. Studies suggest that they might have originated due to the rejuvenation of radial fractures ${ }^{17}$. The DG is 
the most conspicuous compressional deformational signature amongst the wrinkle ridges systems (Dorsum Cushman, Dorsa Cayeux, Dorsa Cato, Dorsa Mawson and Dorsa Andrusov) in its vicinity in a vast region of Mare Fecunditatis and therefore, a structural study of this wrinkle ridge is of utmost importance in order to unveil the deformation history of the region (Figure 2). This ridge represents a broad arc and is a very low multiplebranched ropey ridge ${ }^{18}$. Any detailed study of this wrinkle ridge, except a preliminary estimate of the palaeostress regime responsible for its formation and crustal contraction across $i t^{19}$, is so far absent. The main focus of this study is to describe the structural geometry, accumulated strain, palaeostress regime and age of formation of the dorsa/wrinkle ridge system. Syntheses of the geological information generated have helped us to comment on the evolution of the DG and its implications in the deformation of the adjoining area within Mare Fecunditatis.

\section{Data used and methodology}

Images $(5 \mathrm{~m} / \mathrm{pixel})$ and DEM $(10 \mathrm{~m} / \mathrm{pixel})$ generated by TMC-2 on-board Chandrayaan-2, global mosaic of images by the Lunar Reconnaissance Orbiter Camera-Wide

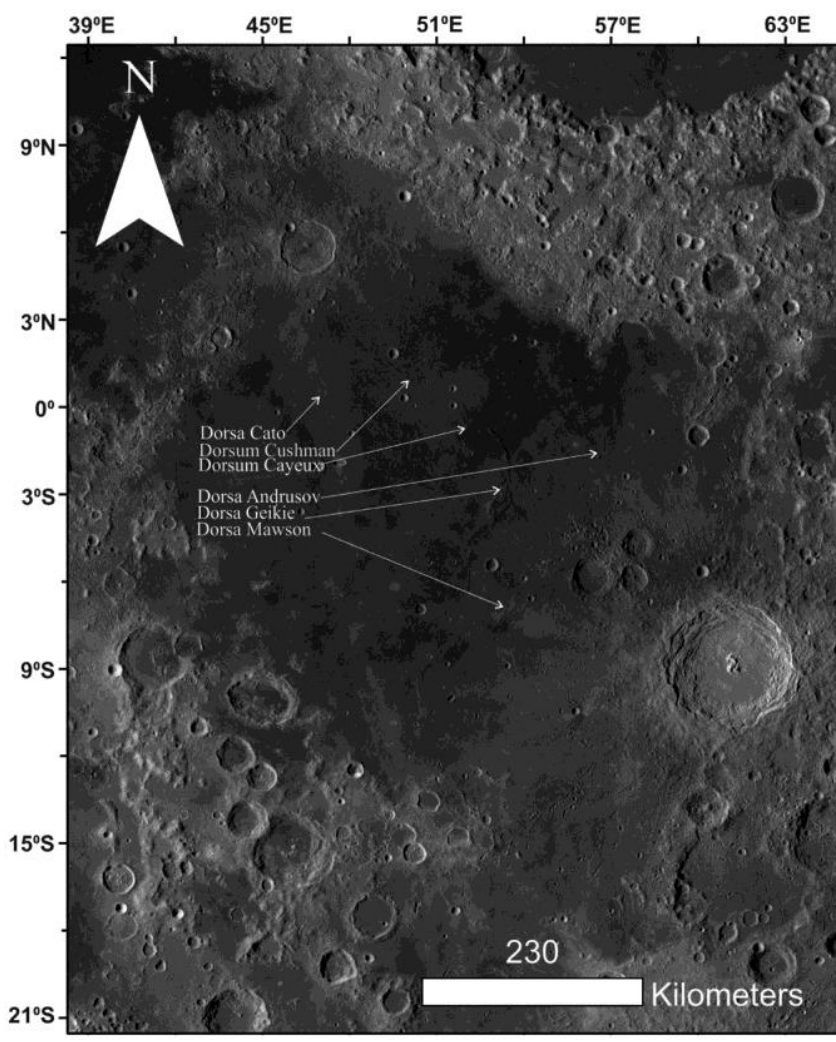

Figure 1. Mare Fecunditatis. Wrinkle ridges within the area are shown. Image ID: Lunar_LRO_LROC-WAC_Mosaic_global_100m_ June2013; 100 m/pixel.
Angle Camera (LROC-WAC; $100 \mathrm{~m} /$ pixel resolution), Lunar Orbiter Laser Altimeter Digital Elevation Model images (LOLA DEM; $114 \mathrm{~m}$ pixel resolution) and LOLA colour shade topography images were used in this study to identify the DG and its morphological properties for delineating the structural geology. LRO consists of one wide-angle camera and two narrow-angle cameras for assessment of landing site in metres up to smaller scales and wavering of polar illumination ${ }^{20,21}$. The LOLA, another payload on-board LROC gives an insight about the topography (DEM) and slope of the lunar surface global$1 y^{22,23}$. TMC-2 ortho-images (ch2_tmc_ndn_2019 1015T102125154360840_d_oth_blr) along with LROCWAC images (Lunar_LRO_LROC-WAC_Mosaic_global_ $100 \mathrm{~m} \_J u n e 2013 ; 100 \mathrm{~m} / \mathrm{pixel}$ ) were used in this study for age determination, identification and trend analysis of the DG while TMC-2 DEM (ch2_tmc_ndn_20191015T 102125154360840_d_oth_blr), LOLA DEM image (Lunar_ LRO_LOLA_Global_LDEM_118m_Mar2014_) and LOLA colour shade image (Lunar_LRO_LOLA_ClrShade_ Global_128ppd_V04) were used for several analyses including estimation of elevation offset, displacementlength scaling and crustal contraction. The LROC WAC image (Lunar_LRO_LROC-WAC_Mosaic_global_100m_ June2013) with $100 \mathrm{~m} /$ pixel resolution was used to estimate the age of the DG using crater size-frequency distribution (CSFD), particularly buffered crater counting

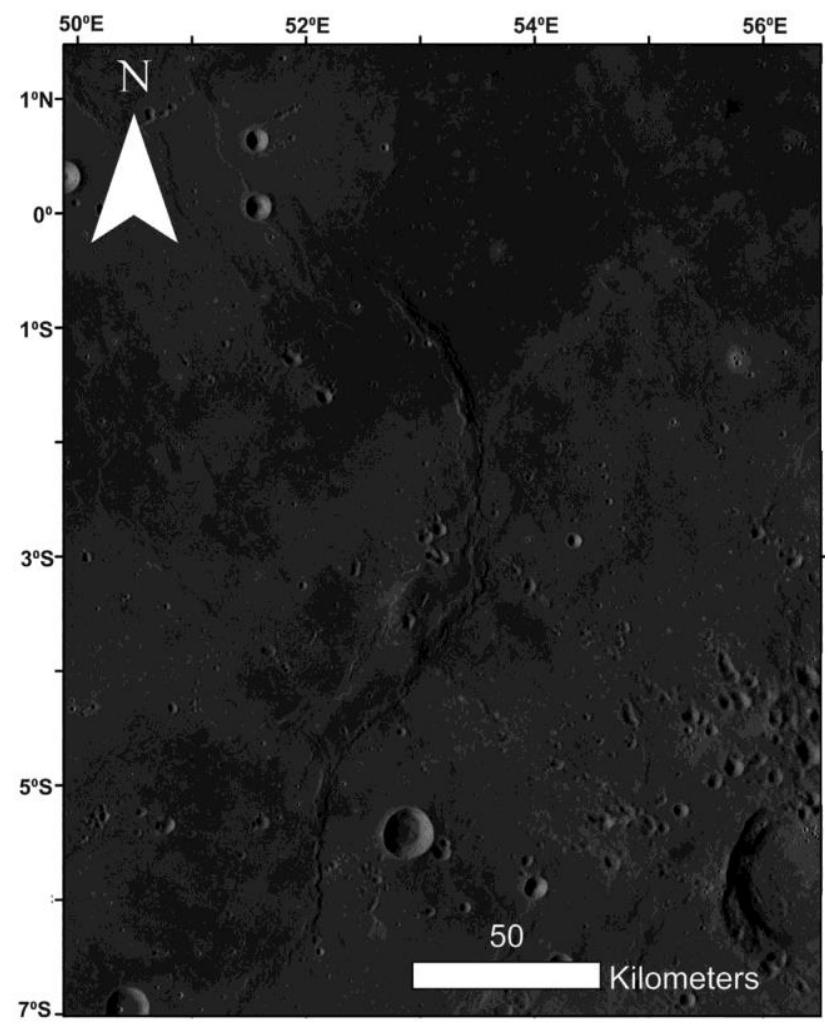

Figure 2. The Dorsa Geikie (DG). Image ID: Lunar_LRO_LROCWAC_Mosaic_global_100m_June2013; $100 \mathrm{~m} /$ pixel. 


\section{RESEARCH ARTICLES}

$(\mathrm{BCC})^{24-26}$ using production function (PF) and chronology function (CF) for the Moon ${ }^{27}$. Crater Tools add-on in ArcGIS was used to map the craters, as three-point inscribed circles, post-dating the DG which was mapped as a polygon. It exports the georeferenced image data for plotting in Craterstats II software. The data generated were statistically analysed using the CraterStats II software ${ }^{24}$

For wrinkle ridges, relationships have been earlier recognized individually between cross-section geometry, kinematic models, depth-to-detachment, and strain accumulated due to thrusting ${ }^{4,28-35}$.

The strikes of the associated fault planes are derived from the orientation of the wrinkle ridge axis ${ }^{36}$. It is suggested that the maximum displacement-length $\left(D_{\max }-L\right)$ scaling can be used for interpretation of long-term equilibrium stress field in the studied region and also for understanding the kinematic control on the growth/ evolution of the wrinkle ridge $e^{6,31}$. Fault displacement is found to be maximum $\left(D_{\max }\right)$ at the middle of fault surface, and there is zero displacement at the tipline of the fault surface ${ }^{32}$. This scaling method implies that a fault population with uniform rock properties maintains a constant $D_{\max }-L$ ratio $^{29,37}$. A $D_{\max }-L$ ratio of $\sim 0.012$ represents thrust faults present on the Moon, whereas it increases up to $\sim 0.023$ for the lunar lobate $\operatorname{scarps}^{7,8,38}$. Study of fault displacement profiles can provide information on the slip of the propagating faults and a reflection of their evolution ${ }^{4,29,31,32,39}$.

Five topographic profiles were extracted through ArcGIS software using the 'line' and the 'create profile graph' button from TMC-2 DEM superposed on LOLA DEM data (Figures 3 and 4). The initial and final lengths from each profile were calculated using the profile curves and simple Moon coordinate system distance methods $s^{40,41}$. We used the mathematical distance formula to find the distance of a line between any two points $A$ and $B$. The equation for the length of a straight line vector between points

$$
\begin{gathered}
A=\left(x_{1}, y_{1}\right) \text { and } B=\left(x_{2}, y_{2}\right) \text { is: } \\
d=\sqrt{\left\{\left(x_{2}-x_{1}\right)^{2}+\left(y_{2}-y_{1}\right)^{2}\right\}},
\end{gathered}
$$

Equation (1) was applied to the shortening/contraction estimation across the DG when it comes to measuring the initial and final lengths from the topographic profiles. The initial length is represented as the length of the curve line in the topographic profiles of the wrinkle ridges.

In order to estimate the curve length, we divided the curve line into infinitesimal number of equal segments with end-points bearing coordinates according to the coordinate system utilized for the same (for this study we used the simple cylindrical Moon projection). The coordinates were saved in Microsoft Excel format (see Supplementary Material). The sum of all infinitesimal lengths was taken simultaneously along the curve. The length was measured mathematically by distance equation based on Pythagoras theorem. The final length is the horizontal distance between endpoints of the profile curve. The line-and-length shortening of the surface across the wrinkle ridge estimated along the section lines is equal to initial length minus final length ${ }^{41}$.

Various structural features depict a deformation style where displacement is found above a region of the detachment zone. Compression causes a regional upliftment creating an excess area (area constant across all regions) and deformation in the lower detachment/ basement zone ${ }^{42}$. Estimation of depth-to-detachment on planetary bodies is ambiguous to an extent, but the principle applied to determine the depth is same as in the terrestrial bodies.

Topographic profiles with vertical offsets well represent the asymmetry of fault-propagation fold profiles. Topographic profiles along traces of the DG similar to Figure $4 d$ and $e$, extracted through ArcGIS were used for the estimation. Such asymmetric profiles indicate fault-propagated folds ${ }^{4}$. For fault tip, we drew a line from the origin at an angle of $25^{\circ}$, considering gentle inclination of the thrust faults in the absence of any subsurface data and following previous works on thrust faults in terrestrial planets $^{6,7,43,44}$. We also drew an imaginary vertical

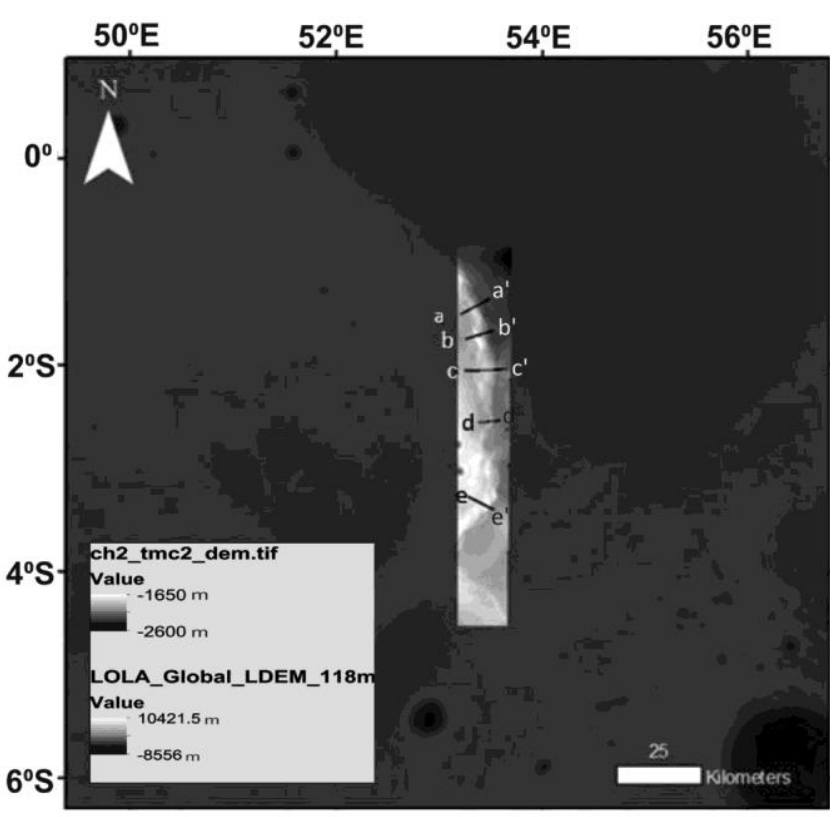

Figure 3. DG and transects $\left(a-a^{\prime}, b-b^{\prime}, c-c^{\prime}, d-d^{\prime}\right.$ and $\left.e-e^{\prime}\right)$ along which profile sections of the DG were extracted for morphometric analyses Image ID: ch2_tmc_ndn_20191015T102125154360840_ d_oth_blr; $10 \mathrm{~m} / \mathrm{pixel}$ resolution and Lunar_LRO_LOLA_Global_ LDEM_118m_Mar2014_; $114 \mathrm{~m}$ pixel resolution. 

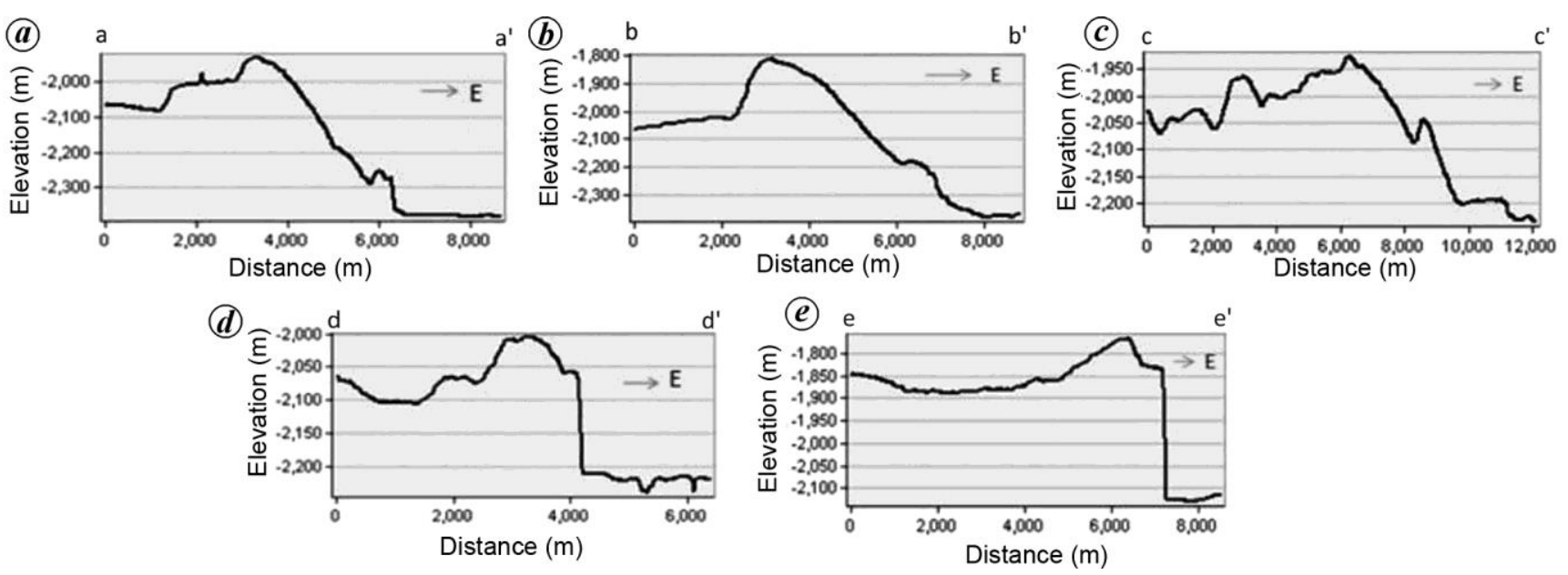

Figure 4. Topographic profiles across the DG extracted along section lines shown in Figure 3.

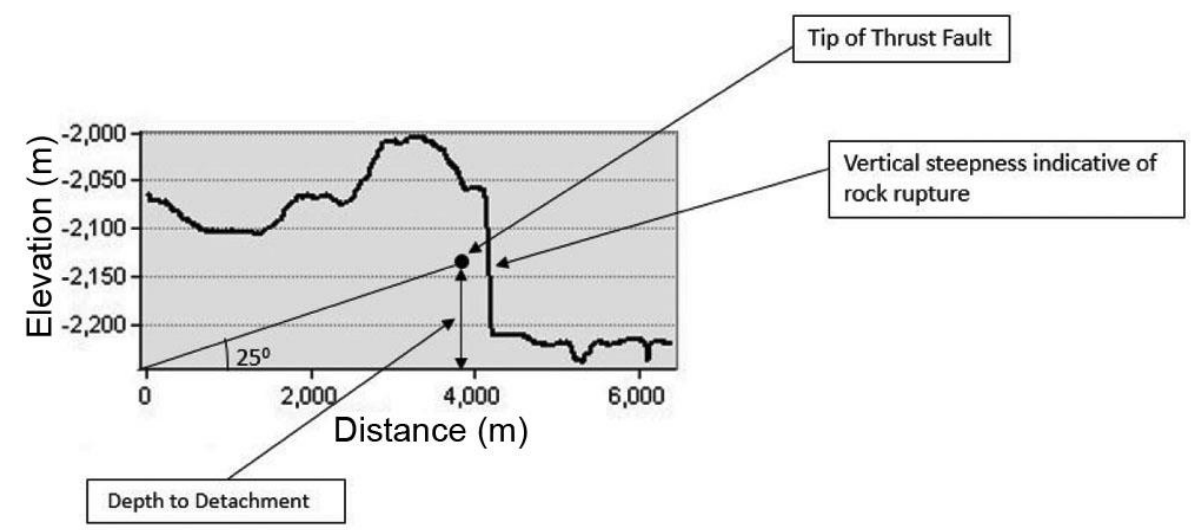

Figure 5. Interpretation of minimum depth to detachment using the blind thrust concept; double arrow gives the distance to depth using eq. (1).

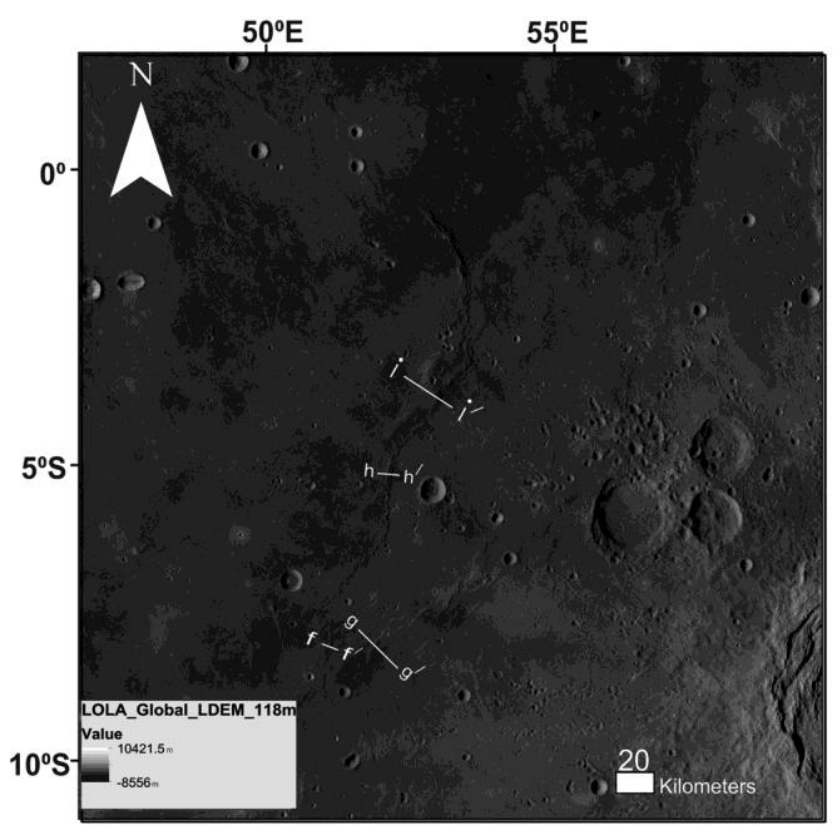

Figure 6. Section lines across the DG and adjoining wrinkle ridges. Topographic profiles along these section lines are presented in Figure 7. Image ID: Lunar_LRO_LROC-WAC_Mosaic_global_ $100 \mathrm{~m} \_J u n e 2013$; with $100 \mathrm{~m} /$ pixel resolution. line perpendicular from the tip of the fault downwards $\left(\operatorname{dip}=25^{\circ}\right)$ till it met the horizontal axis. The coordinates of the end-points were used in eq. (1) and Figure 5 to estimate the depth-to-detachment of the wrinkle ridge.

Morphometric analyses of wrinkle ridges were also carried out to estimate the degree of compression or contractional strain of the mare region, as the wrinkle ridges are the only large-scale compressional structures present mostly within the mare ${ }^{45}$. Four wrinkle ridges in proximity of the DG (the DG and three adjacent unnamed ridges) were considered to estimate the maximum displacement-length ratio $\left(D_{\max }-L\right.$ ratio $)$ and the total contractional strain accumulated in the area in its (the DG) near bound, including the nature of the fault involved (Figure $6)^{6,46}$. The reason for selection of the wrinkle ridges was based on their adjacency and similarity in alignment that could reflect a single compressional regime. Assuming, in the absence of subsurface data, that the slope angle or dip of the thrust fault responsible for formation of the wrinkle ridge is $25^{\circ}$ (refs 6,43 and 44)

$$
D=\text { Vertical offset }(\mathrm{m}) / \sin \theta^{26,29}
$$



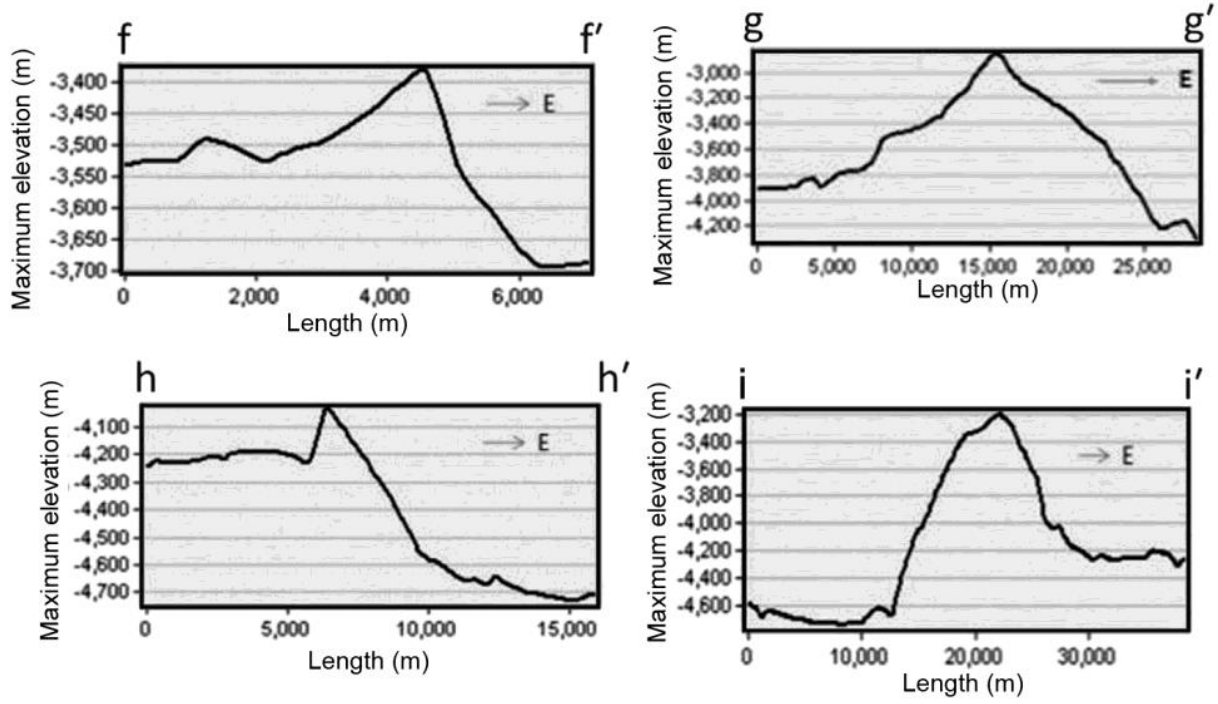

Figure 7. Topographic profiles of the DG and adjoining wrinkle ridges along the section lines shown in Figure 6.

To attain the objective of $D_{\max }-L$ scaling, profiles showing maximum vertical offset $(\mathrm{m})$ across the four wrinkle ridges (Figures 6 and 7) were selected to estimate $D$ from eq. (2) above; $\theta$ was taken as $25^{\circ}$. The lengths of horizontal traces of the wrinkle ridges observed through DEM and global mosaic were considered as the length $(L)$ and measured using ArcGIS measurement tool ${ }^{36,47}$.

The $D_{\max }-L$ plot was obtained using Microsoft Excel.

Studies have shown that $D_{\max }-L$ scaling applied to terrestrial faults can also be applied to faults on planetary bodies and is represented by

$$
D_{\max }=c L^{n},
$$

where $n>1$ and $c$ is a constant reflecting material properties $^{6,29,48}$. For faults developed in uniform rock materials, the relationship is found to be linear as ${ }^{29}$

$$
D_{\max }=\gamma L
$$

where $\gamma=c$ (constant).

The contractional strain $(\varepsilon)$ for the DG together with the adjoining wrinkle ridges in Mare Fecunditatis was calculated using the following equation

$$
\varepsilon=\frac{\cos (\theta)}{A} \sum_{k=1}^{n} D_{k} L_{k}
$$

where $\theta$ is the slope of the fault (taken as $25^{\circ}$ for the thrust fault) ${ }^{6,43}, A$ the area studied and $n$ is total number of faults ${ }^{46}$.

In order to decipher the orientation of principal stresses in the palaeo-stress regime responsible for the origin of the thrust fault beneath the dorsa the Anderson's theory of faulting that relates the principal stresses with the fault plane was followed ${ }^{44}$. The orientations of the segments of the wrinkle ridge axes were measured in ArcGIS software and used in the estimation of the palaeo-stress direction in the T-Tecto 3.0 open source software ${ }^{49}$.

It has been proposed that wrinkle ridges had formed in the late stage of deformation of the lunar surface s5,50. $^{35}$. However, no consensus on their lower and upper age limits has been reached so $\operatorname{far}^{7,8,51}$. In order to determine the age of such tectonic features CSFD is the most widely used technique for estimation of the age of planetary surfaces $^{24,25,52-54}$. In the CSFD technique, all superimposed craters with their centres located inside a geologically homogeneous area chosen for determination of age are considered for counting. Crater statistics obtained by crater counting is then fitted with a known crater production function ${ }^{24}$. In order to obtain the absolute age, the crater frequency for certain crater sizes is then combined with the chronology function ${ }^{27}$. The BCC, a modified CSFD technique, is used to estimate the age of the $\mathrm{DG}^{25,54}$. In principle, $\mathrm{BCC}$ is categorically used for estimation of age of linear features (fluvial, tectonic and crater-rims) which commonly have limited number of superimposed impact craters $^{26,53-56}$. The original BCC technique has been modified by selecting specific areas where the craters postdating the linear features are only considered ${ }^{25,54,55}$. In this study BCC, excluding the secondary craters, with buffer width of 1.5 times the crater radii of the DG has been done using ArcGIS crater tools add-on and the age analysis done with CraterStats II software ${ }^{24-26}$. The total buffered area from where the craters were counted is $1.97 \times 10^{3}$ sq. $\mathrm{km}$ and the range of radius of the craters is $300 \mathrm{~m}$ to $3 \mathrm{~km}$.

\section{Results}

Table 1 represents the line-and-length contraction of the surface across the DG. Average contraction percentage of the DG was $1.89 \%$, which is in conformity with the 
Table 1. Estimation of line-and-length contraction of the surface across the Dorsa Geikie

\begin{tabular}{lcccc}
\hline $\begin{array}{l}\text { Wrinkle ridge } \\
\text { profiles }\end{array}$ & $\begin{array}{c}\text { Initial length, } \\
L_{0}(\mathrm{~m})\end{array}$ & $\begin{array}{c}\text { Final length, } \\
L_{1}(\mathrm{~m})\end{array}$ & $\begin{array}{c}\text { Contraction } \\
(m)=L_{0}-L_{1}\end{array}$ & Contraction $(\%)$ \\
\hline$a-a^{\prime}$ & $8,805.917$ & $8,666.081$ & 139.8363 & 1.59 \\
$b-b^{\prime}$ & $8,928.111$ & $8,788.805$ & 139.3056 & 1.56 \\
$c-c^{\prime}$ & $12,168.47$ & 12,074 & 94.05437 & 0.77 \\
$d-d^{\prime}$ & $6,513.986$ & $6,381.684$ & 132.3023 & 2.03 \\
$e-e^{\prime}$ & $8,684.698$ & $8,377.746$ & 306.9519 & 3.53 \\
Average contraction $(\%)$ & & & & 1.896 \\
\hline
\end{tabular}

Table 2. Estimation of maximum displacement, vertical offset and length for $D_{\max }-L$ scaling

\begin{tabular}{lccc}
\hline $\begin{array}{l}\text { Wrinkle ridge } \\
\text { profile number }\end{array}$ & Length $(\mathrm{m})$ & Vertical offset $(\mathrm{m})$ & $\begin{array}{c}\text { Displacement } \\
(\mathrm{m})\end{array}$ \\
\hline$f-f^{\prime}$ & 85,379 & 130 & 307.61 \\
$g-g^{\prime}$ & 250,090 & 800 & $1,892.96$ \\
$h-h^{\prime}$ & 95,801 & 180 & 425.92 \\
$i-i^{\prime}$ & 330,214 & 1,100 & $2,602.82$ \\
\hline
\end{tabular}

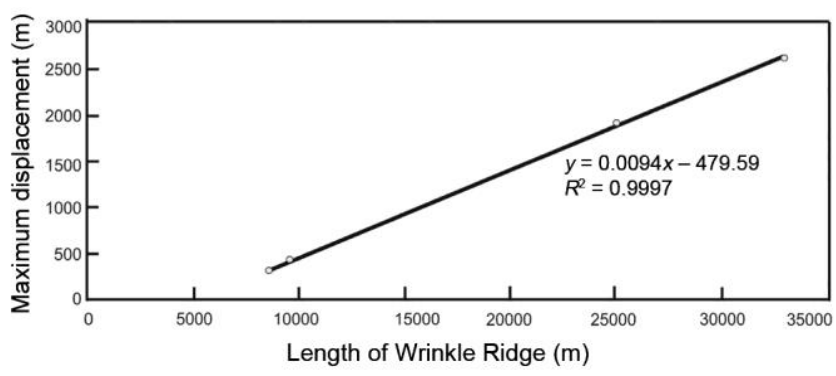

Figure 8. Maximum displacement versus length scaling for the DG and adjoining ridges.

average total accumulated contraction across the lunar wrinkle ridges $(-0.26 \% \text { to } 3.6 \%)^{57}$. The contraction percentage was minimum at mid profile, while the shortening value was maximum towards the southern end of the DG.

The $D_{\max }-L$ scaling ratio utilizing four wrinkle ridges (Figure 6) was estimated to be 0.009 as determined from the following equation (Figure 8)

$$
y=0.0094 x-479.59, R^{2}=0.9997 .
$$

Equation (6) is a linear regression equation that predicts the relationship between two variables (here displacement on faults and length of faults; length of the wrinkle ridge is taken as the length of the fault underneath) and $R^{2}$ value determines the intensity of the relationship. Values of $R^{2}$ close to or equal to 1 indicate strong relationship between the two variables ${ }^{58}$. Table 2 shows that fault displacement is directly proportional to the length of the fault trace, indicating a single fault and uniform rock material in which the fault was formed ${ }^{29,32}$.

With $\gamma=0.009$ as determined from the maximum displacement scaling plot and fault $\operatorname{dip} \theta=25$; the contractional strain was estimated to be $0.60 \%$; the value is relatively higher than $\sim 0.36 \%$ and $\sim 0.14 \%$ for wrinkle ridges in Mare Serenitatis and Mare Tranquillitatis respectively ${ }^{6}$.

Depth-to-detachment of the thrust fault beneath the DG was found to be in the range $91-150 \mathrm{~m}$ along the fault trace. With crustal thickness of Mare Fecunditatis in the vicinity of the DG being 500-800 m, the estimated values of depth to detachment might be a possibility. Also, the $D_{\text {max }}-L$ plot with a constant value of $R^{2}=0.997$ (Figure 8) conforms to the plot type suggested for thrust faults $^{59,60}$ which dip towards $\mathrm{SW}$, as understood from elevation offsets ${ }^{61}$.

Estimation of the palaeostress regime responsible for the formation of this wrinkle ridge showed that the maximum principal stress $\left(\sigma_{1}\right)$ was ENE-WSW trending horizontal and the minimum principal stress was vertical (Figure 9).

The age of the DG was estimated to be in the range 3.1-3.4 Ga, where $3.4 \mathrm{Ga}$ is the maximum best fit with buffer width of 1.5 times the crater radii and crater count of 180 (Figures 10 and 11).

\section{Discussion}

Wrinkle ridges are surface expressions of thrust faulting which resulted from compressional stress. Wrinkle ridges on the Moon that continued to form since 3.5 to $\sim 1.2 \mathrm{Ga}$ occur within and around the mare ${ }^{7}$. The DG, therefore, like any other wrinkle ridge on the lunar surface is representative of the long history of global contraction which was dominantly basin localized. The ridges are often linked, capped or coupled by smaller second order wrinkle ridges ${ }^{62}$. The basin of Mare Fecunditatis is pre-Nectarian (4.9-3.8 Ga), while the mare age is middle to late Imbrian $^{14}$. Initiation of mare volcanism in the Fecunditatis basin occurred at $2.68 \mathrm{Ga}$ (ref. 35).

Therefore, the DG (3.4 Ga; with crater counts of 180 in this study) might have formed $\sim 0.28 \mathrm{Ga}$ after the initiation of basaltic volcanism in the Fecunditatis basin. Since the basin is very old and degraded, many wrinkle ridges have also been mutilated, submerged and estimation of linear dimension is always an uncertainty. However, DEMs from TMC-2 and LOLA have helped trace the 
horizontal extension of the DG. The DG stands as an early formed wrinkle ridge in the lunar mare as indicated by our CSFD estimate. Apart from the tidal recession and diurnal tidal stresses, the onset of global contraction post $3.6 \mathrm{Ga}$ is generally considered as a combination of



Figure 9. Stereographic projection showing orientation of principal stresses in the palaeostress regime responsible for origin of the trust fault that caused the formation of the DG. Each great circle represents a small segment of the fault with strike parallel to a mapped straigh segment of the wrinkle ridge axis. Dip of fault is assumed as $25^{\circ}$. Thin arrows within the projection indicate slip lines. Total number of data is 11 . Trend data of the DG axis are presented in Supplementary Material.

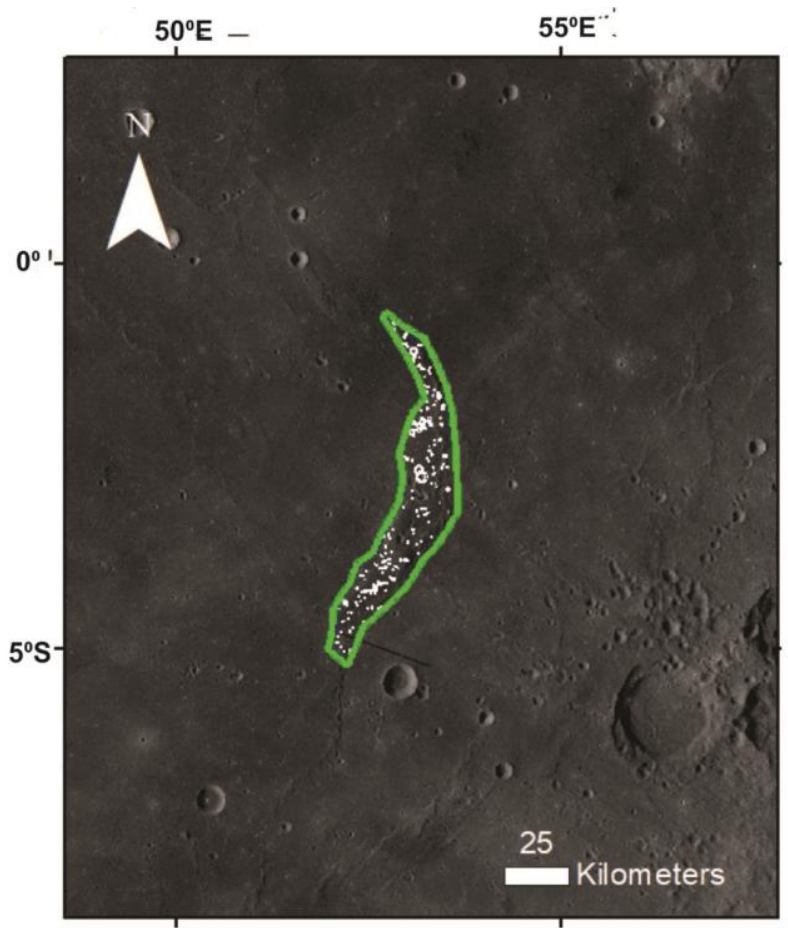

Figure 10. Crater count on the DG for buffered crater counting (BCC) approach, buffering with 1.5 times crater radii. Image ID: Lunar_LRO_LROC-WAC_Mosaic_global_100m_June2013 with $100 \mathrm{~m} /$ pixel resolution. flexural slip folding (isostasy) and local/global compressional stresses which may be responsible for the formation of the $\mathrm{DG}^{9,10,63}$. Compressional forces mainly acted in the ENE-WSW direction and in large scales as can be seen from the wrinkle ridge population in the eastern part of Mare Fecunditatis. Shortening percentage varied

between 0.77 and 3.53 for the DG. Depth-to-detachment estimate reflects that the crust is thin. Also, $D_{\max }-L$ ratio of thrust faults on the Moon was found to be in the range $0.001-0.012$ based on the $25^{\circ}$ dip angle of the thrust fault $^{6-8}$. Such studies are important for understanding the global contractional strain experienced by the wrinkle ridges on the Moon, obtained from thrust fault mapping ${ }^{64}$. Higher values of contractional strain $(0.60 \%)$ in the studied area of the wrinkle ridges in Mare Fecunditatis indicate more intense and/or more prolonged active compressional stress in ENE-WSW orientation. Also, the $D_{\max }-L$ plot with the constant value of $R^{2}=0.997$ conforms with the plot type designed for major thrust faults $^{31,59,60}$. In maximum displacement-length scaling method, a single large fault is often indicated if displacement increases with increase in the length of the structural feature (thrust fault here) ${ }^{29}$. Such results might also involve different fault growth mechanisms and greater mechanical interaction, including strain localization on larger thrust faults ${ }^{31}$. This study reveals that an isolated, single, large thrust fault was responsible for the formation of the DG through upward arching of
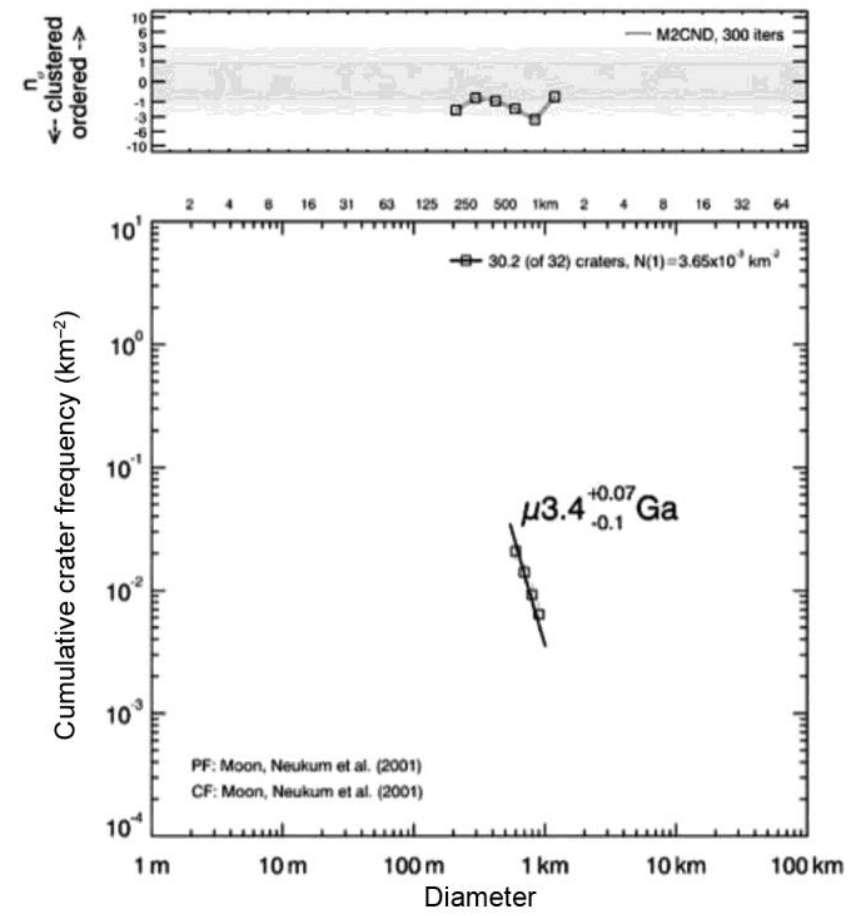

Figure 11. The crater size-frequency distributions and derived model age of the DG determined using BCC method with 1.5 times crater radii as the buffer width. Crater retention age $N(1)=3.49 \times 10^{-3}$. PF, Production function; $\mathrm{CF}$, Chronology function. 
surface by fault-propagated fold mechanism which is shortening accomplished by folding ${ }^{4}$ causing an average $1.89 \%$ crustal contraction across the dorsa (Table 1). Also, the linear relationship in maximum displacementlength scaling indicates uniform rock material. Although, this study is an initial analysis of the data received from TMC-2, it presents a detailed account of the structural evolution of the DG. Such analysis could be done for all possible wrinkle ridges on the Moon so as to determine the quantum of overall lunar shrinkage in the past.

1. Chowdhury, A. R. et al., Terrain mapping camera-2 onboard Chandrayaan-2 orbiter. Curr. Sci., 2020, 118(4), 566.

2. International Astronomical Union, Dorsa Geikie, Gazetteer of Planetary Nomenclature, Working Group for Planetary System Nomenclature, 1976

3. Bryan, W. B., Wrinkle-ridges as deformed surface crust on ponded mare lava. Lunar Planet. Sci. Conf. Proc., 1973, 4, 93.

4. Schultz, R. A., Localization of bedding plane slip and backthrust faults above blind thrust faults: keys to wrinkle ridge structure. J. Geophys. Res.: Planets, 2000, 105(E5), 12035-12052; https:// doi.org/10.1029/1999JE001212.

5. Williams, N. R., Shirzaei, M., Bell III, J. F. and Watters, T. R., Inverse modeling of wrinkle ridge structures on the Moon and Mars. In AGU Fall Meeting Abstracts, Abstract id: P33C-2141, 2015.

6. Li, B., Ling, Z., Zhang, J., Chen, J., Ni, Y. and Liu, C., Displacement-length ratios and contractional strains of lunar wrinkle ridges in mare serenitatis and mare tranquillitatis. J. Struct. Geol., 2018, 109, 27-37.

7. Watters, T. R., Johnson, C. L. and Schultz, R. A., Lunar tectonics. In Planetary Tectonics (ed. Watters, T. R.), Cambridge University Press, 2010, vol. 11, pp. 11; 121.

8. Watters, T. R. et al., Evidence of recent thrust faulting on the Moon revealed by the lunar reconnaissance orbiter camera. Science, 2010, 329(5994), 936-940; doi:10.1126/science.1189590.

9. Solomon, S. C. and Head, J. W., Vertical movement in mare basins: relation to mare emplacement, basin tectonics, and lunar thermal history. J. Geophys. Res.: Solid Earth, 1979, 84(B4), 1667-1682; https://doi.org/10.1029/JB084iB04p01667.

10. Solomon, S. C. and Head, J. W., Lunar mascon basins: lava filling, tectonics, and evolution of the lithosphere. Rev. Geophys., 1980, 18(1), 107-141; https://doi.org/10.1029/RG018i001p00107.

11. Head III, J. W. and Wilson, L., Lunar mare volcanism: stratigraphy, eruption conditions, and the evolution of secondary crusts. Geochim. Cosmochim. Acta, 1992, 56(6), 2155-2175; https://doi.org/10.1016/0016-7037(92)90183-J.

12. Whitford-Stark, J. L., The geology of the lunar mare Fecunditatis. Lunar and Planetary Science Conference, Texas, USA, 1986, vol. 17, pp. 940-941.

13. Carr, M. H., Saunders, R. S., Strom, R. G. and Wilhelms, D. E., The geology of the terrestrial planets, Jet Propulsion Laboratory, NASA, USA, 1984, pp. 107-206.

14. Hiesinger, H., Head III, J. W., Wolf, U., Jaumann, R. and Neukum, G., New ages for basalts in Mare Fecunditatis based on crater size-frequency measurements. In Lunar and Planetary Science Conference, Texas, USA, 2006, vol. XXXVII, abstr. $\# 1151$.

15. Cadogan, P. H. and Turner, G., ${ }^{40} \mathrm{Ar}-{ }^{39} \mathrm{Ar}$ dating of LUNA 16 and LUNA 20 samples. Philos. Trans. R. Soc. London, Ser. A: Math. Phys. Sci., 1977, 284(1319), 167-177; https://doi.org/10.1098/ rsta.1977.0007

16. Fernandes, V. A. and Burgess, R., Volcanism in mare fecunditatis and mare crisium: $\mathrm{Ar}-\mathrm{Ar}$ age studies. Geochim. Cosmochim.
Acta, 2005, 69(20), 4919-4934; https://doi.org/10.1016/j.gca. 2005.05.017.

17. Mason, R., Guest, J. E. and Cooke, G. N., An imbrium pattern of graben on the Moon. Proc. Geologists' Assoc., 1976, 87(2), 161168; https://doi.org/10.1016/S0016-7878(76)80008-9.

18. Garfinkle, R. A., Observing lunar wrinkle ridges. In Luna Cogni$t a$, Springer, New York, USA, 2020, pp. 979-992; https://doi.org/ 10.1007/978-1-4939-1664-1_27.

19. Arya, A. S. et al., Morpho-tectonic evaluation of Dorsa-Geiki wrinkle ridge using Terrain Mapping Camera-2 onboard Chandryaan-2. In Lunar and Planetary Science Conference, Texas, USA, 2020, abstr. \#1386.

20. Chin, G. et al., Lunar reconnaissance orbiter overview: The instrument suite and mission. Space Sci. Rev., 2007, 129(4), 391-419.

21. Robinson, M. S. et al., Lunar reconnaissance orbiter camera (LROC) instrument overview. Space Sci. Rev., 2010, 150(1-4), 81-124.

22. Riris, H. et al., The lunar orbiter laser altimeter (LOLA) on NASA's lunar reconnaissance orbiter (LRO) mission. In Conference on lasers and Electro-optics. Optical Society of America, San Jose, USA, 2008, p. CMQ1.

23. Smith, D. E. et al., Initial observations from the lunar orbiter laser altimeter (LOLA). Geophys. Res. Lett., 2010, 37(18), L18204.

24. Michael, G. G. and Neukum, G., Planetary surface dating from crater size-frequency distribution measurements: partial resurfacing events and statistical age uncertainty. Earth Planet. Sci. Lett., 2010, 294(3-4), 223-229.

25. Kneissl, T., van Gasselt, S. and Neukum, G., Map-projectionindependent crater size-frequency determination in GIS environments - new software tool for ArcGIS. Planet. Space Sci., 2011, 59(11-12), 1243-1254; https://doi.org/10.1016/j.pss.2010.03.015.

26. Ruj, T., Komatsu, G., Pondrelli, M., Di Pietro, I. and Pozzobon, R., Morphometric analysis of a Hesperian aged Martian lobate scarp using high-resolution data. J. Struct. Geol., 2018, 113, 1-9; https://doi.org/10.1016/j.jsg.2018.04.018.

27. Neukum, G., Ivanov, B. A. and Hartmann, W. K., Cratering records in the inner solar system in relation to the lunar reference system. In Chronology and Evolution of Mars (eds Kallenbach, R., Geiss, J. and Hartmann, W. K.), Proceedings of an ISSI Workshop, Bern, Switzerland, 2000.

28. Chamberlin, R. T., 1910. The Appalachian folds of central Pennsylvania. J. Geol., 2001, 18(3), 228-251.

29. Cowie, P. A. and Scholz, C. H., Displacement-length scaling relationship for faults: data synthesis and discussion. J. Struct. Geol., 1992, 14(10), 1149-1156; https://doi.org/10.1016/01918141(92)90066-6.

30. Clark, R. M. and Cox, S. J. D., A modern regression approach to determining fault displacement-length scaling relationships. $J$. Struct. Geol., 18(2-3), 147-152; https://doi.org/10.1016/S01918141(96)80040-X

31. Kim, Y. S., Peacock, D. C. and Sanderson, D. J., Fault damage zones. J. Struct. Geol., 1996, 26(3), 503-517; https://doi.org/ 10.1016/j.jsg.2003.08.002.

32. Kim, Y. S. and Sanderson, D. J., The relationship between displacement and length of faults: a review. Earth-Sci. Rev., 2005, 68(3-4), 317-334; https://doi.org/10.1016/j.earscirev.2004.06.003.

33. Schultz, R. A., Okubo, C. H. and Wilkins, S. J., Displacementlength scaling relations for faults on the terrestrial planets. J. Struct. Geol., 2006, 28(12), 2182-2193; https://doi.org/10.1016/ j.jsg.2006.03.034.

34. Yue, Z., Li, W., Di, K., Liu, Z. and Liu, J., Global mapping and analysis of lunar wrinkle ridges. J. Geophys. Res.: Planets, 2015, 120(5), 978-994.

35. Yue, Z., Michael, G. G., Di, K. and Liu, J., Global survey of lunar wrinkle ridge formation times. Earth Planet. Sci. Lett., 2017, 477, 14-20; https://doi.org/10.1016/j.epsl.2017.07.048.

36. Dasgupta, D., Kundu, A., De, K. and Dasgupta, N., Polygonal impact craters in the Thaumasia Minor, Mars: role of pre-existing 


\section{RESEARCH ARTICLES}

faults in their formation. J. Indian Soc. Remote Sensing, 2018 , 47(2), 257-265; https://doi.org/10.1007/s12524-018-0919-3.

37. Dawers, N. H., Anders, M. H. and Scholz, C. H., Growth of normal faults: displacement-length scaling. Geology, 1993, 21(12), 1107-1110; https://doi.org/10.1130/0091-7613(1993)021\%3C1107: GONFDL\%3E2.3.CO;2.

38. Roggon, L., Hetzel, R., Hiesinger, H., Clark, J. D., Hampel, A and van der Bogert, C. H., Length-displacement scaling of thrust faults on the Moon and the formation of uphill-facing scarps. Icarus, 2017, 292, 111-124; https://doi.org/10.1016/j.icarus.2016. 12.034

39. Peacock, D. C. P. and Sanderson, D. J., Displacements, segment linkage and relay ramps in normal fault zones. J. Struct. Geol., 1991, 13(6), 721-733; https://doi.org/10.1016/0191-8141(91) 90033-F.

40. Moon, P. and Spencer, D. E., Field Theory Handbook: Including Coordinate Systems, Differential Equations and their Solutions, Springer, 2012.

41. Marshak, S. and Mitra, G., Basic Methods of Structural Geology, Prentice Hall, New Jersey, USA, 1988

42. Epard, J. L. and Groshong Jr, R. H., Excess area and depth to detachment. AAPG Bull., 1993, 77(8), 1291-1302; https://doi.org/ 10.1306/BDFF8E66-1718-11D7-8645000102C1865D.

43. Dunne, W. M. and Ferrill, D. A., Blind thrust systems. Geology, 1988, 16(1), 33-36; https://doi.org/10.1130/0091-7613(1988) 016\%3C0033:BTS\%3E2.3.CO;2.

44. Anderson, E. M., The dynamics of faulting. Trans. Edin. Geol. Soc., 1905, 8(3), 387-402.

45. Plescia, J. B. and Golombek, M. P., Origin of planetary wrinkle ridges based on the study of terrestrial analogs. Geol. Soc. Am. Bull., 1986, 97(11), 1289-1299; https://doi.org/10.1130/00167606(1986)97\%3C1289:OOPWRB\%3E2.0.CO;2

46. Scholz, C. H., Dawers, N. H., Yu, J. Z., Anders, M. H. and Cowie, P. A., Fault growth and fault scaling laws: preliminary results. J. Geophys. Res.: Solid Earth, 1993, 98(B12), 21951-21961; https://doi.org/10.1029/93JB01008.

47. Schultz, R. A. and Fossen, H., Displacement-length scaling in three dimensions: the importance of aspect ratio and application to deformation bands. J. Struct. Geol., 2002, 24(9), 1389-1411; https://doi.org/10.1016/S0191-8141(01)00146-8.

48. Gillespie, P. A., Walsh, J. T. and Watterson, J., Limitations of dimension and displacement data from single faults and the consequences for data analysis and interpretation. J. Struct. Geol., 1992, 14, 1157-1157.

49. Žalohar, J., T-TECTO 3.0 professional integrated software for structural analysis of fault-slip data. Introductory Tutorial, 2009, p. 56.

50. Fagin, S. W., Worrall, D. M. and Muehlberger, W. R., Lunar mare ridge orientation-implications for lunar tectonic models. In Lunar and Planetary Science Conference Proceedings, Texas, USA, 1978, vol. 9, pp. 3473-3479.

51. Ono, T. et al., Lunar radar sounder observations of subsurface layers under the nearside maria of the Moon. Science, 2009, 323(5916), 909-912; doi:10.1126/science.1165988.

52. Hartmann, W. K. and Neukum, G., Cratering chronology and the evolution of Mars. In Chronology and Evolution of Mars, Springer, Dordrecht, The Netherlands, 2001, pp. 165-194.

53. Kneiss1, T. and Michael, G., Crater size-frequency measurements on linear features: buffered crater counting in ArcGIS. In 44th
Lunar and Planetary Science Conference, Texas, USA, 2013, abstr. \#1079.

54. Kneiss1, T., Michael, G. G., Platz, T. and Walter, S. H. G., Age determination of linear surface features using the buffered crater counting approach - case studies of the Sirenum and Fortuna Fossae graben systems on Mars. Icarus, 2015, 250, 384-394; https://doi.org/10.1016/j.icarus.2014.12.008.

55. Fassett, C. I. and Head III, J. W., The timing of martian valley network activity: constraints from buffered crater counting. Icarus, 2008, 195(1), 61-89.

56. Fassett, C. I., Head, J. W., Kadish, S. J., Mazarico, E., Neumann, G. A., Smith, D. E. and Zuber, M. T., Lunar impact basins: stratigraphy, sequence and ages from superposed impact crater populations measured from Lunar Orbiter Laser Altimeter (LOLA) data. J. Geophys. Res.: Planets, 2012, 117(E12), E00806.

57. Golombek, M. P., Plescia, J. B. and Franklin, B. J., Faulting and folding in the formation of planetary wrinkle ridges. In Lunar and Planetary Science Conference Proceedings, Texas, USA, 1991, vol. 21, pp. 679-693.

58. Browne, M. W., Predictive validity of a linear regression equation. Br. J. Math. Stat. Psychol., 1975, 28(1), 79-87.

59. Elliott, D., The motion of thrust sheets. J. Geophys. Res., 1976, 81(5), 949-963; doi:10.1029/JB081i005p00949.

60. Scholz, C. H. and Cowie, P. A., Determination of total strain from faulting using slip measurements. Nature, 1990, 346(6287), $837-$ 839.

61. Golombek, M. P., Anderson, F. S. and Zuber, M. T., Martian wrinkle ridge topography: evidence for subsurface faults from MOLA. J. Geophys. Res.: Planets, 2001, 106(E10), 23811-23821; https://doi.org/10.1029/2000JE001308.

62. Watters, T. R., Wrinkle ridge assemblages on the terrestrial planets. J. Geophys. Res.: Solid Earth, 1988, 93(B9), 1023610254.

63. Maxwell, T. A., El-Baz, F. and Ward, S. H., Distribution, morphology, and origin of ridges and arches in Mare Serenitatis. Geol. Soc. Am. Bull., 1975, 86(9), 1273-1278; https://doi.org/ 10.1130/0016-7606(1975)86\%3C1273:DMAOOR\%3E2.0.CO;2.

64. Klimczak, C., Limits on the brittle strength of planetary lithospheres undergoing global contraction. J. Geophys. Res.: Planets, 2015, 120(12), 2135-2151; https://doi.org/10.1002/2015JE004851.

ACKNOWLEDGEMENTS. We thank Shri N. M. Desai (Director, Space Applications Centre (SAC), Ahmedabad) for inspiration and support and Dr Rajkumar (former Deputy Director, SAC) for guidance. We also thank SSPO, Indian Space Research Organisation (ISRO), Bengaluru, for support and scientific interactions; the Data Products Team and the Payload Team at SAC and ISRO mission team at URSC/ISTRAC, Bengaluru for helping in executing imaging plans, data acquisition, generation of $\mathrm{LO}$ products, etc. This paper is an outcome of a collaborative research project of SAC, with the Planetary Geology Laboratory, Asutosh College, Kolkata. J.T. thanks Shri Dipayan Dasgupta, Research Fellow, Department of Geology, Asutosh College, for assistance.

Received 16 February 2021; revised accepted 20 March 2021

doi: $10.18520 / \mathrm{cs} / \mathrm{v} 121 / \mathrm{i} 1 / 94-102$ 